\title{
Características agronômicas e morfológicas de cafeeiro 'Catuaí Vermelho' propagado por embriogênese somática
}

\author{
Carlos Henrique Siqueira de Carvalho(1), Juliana Costa de Rezende(2), Gustavo Rennó Reis Almeida(3), \\ João Batista Teixeira ${ }^{(4)}$ e Lilian Padilha ${ }^{(1)}$
}

(1)Embrapa Café, Alameda do Café, № 1.000, CEP 37026-400 Varginha, MG. E-mail: carlos.carvalho@embrapa.br, lilian.padilha@embrapa.br (2)Empresa de Pesquisa Agropecuária de Minas Gerais, Campus da Universidade Federal de Lavras, s/no, Caixa Postal 176, CEP 37200-000 Lavras, MG. E-mail: julianacosta@epamig.br (3)Cooperativa dos Cafeicultores da Zona de Varginha, Rua Silvio Cougo, no 680, Vila Paiva, CEP 37018-020 Varginha, MG. E-mail: renno@minasul.com.br (4)Embrapa Recursos Genéticos e Biotecnologia, Parque Estação Biológica (PqEB), Avenida W5 Norte (final), s/nº, CEP 70770-200 Brasília, DF. E-mail: batista@cenargen.embrapa.br

Resumo - O objetivo deste trabalho foi avaliar características agronômicas e morfológicas de plantas de Coffea arabica, cultivar Catuaí Vermelho IAC 44, propagadas por embriogênese somática. O experimento foi instalado em janeiro de 2005, em delineamento experimental de blocos ao acaso, com dez repetições. As plantas foram avaliadas mensalmente quanto ao desenvolvimento vegetativo, de junho de 2005 a janeiro de 2006, e as avaliações agronômicas foram realizadas dois anos e meio após o início do experimento. A produtividade de grãos foi avaliada durante as quatro primeiras colheitas. Cafeeiros provenientes de embriogênese somática apresentam desenvolvimento inicial mais rápido do que as plantas obtidas de sementes e, aos 30 meses após plantio no campo, têm diâmetro de copa superior ao de plantas de origem seminal. O desempenho agronômico de plantas de $C$. arabica produzidas por embriogênese somática é semelhante ao de plantas oriundas de sementes, e não há restrições agronômicas para a sua utilização.

Termos para indexação: Coffea arabica, crescimento vegetativo, produção, propagação.

\section{Agronomic and morphological traits of 'Catuaí Vermelho' coffee plant propagated by somatic embryogenesis}

\begin{abstract}
The objective of this work was to assess agronomical and morphological traits of Coffea arabica plants, cultivar Catuaí Vermelho IAC 44, propagated by somatic embryogenesis. The experiment was established in January 2005 in a randomized complete block design, with 10 replicates. Plants were evaluated monthly for vegetative development, from June 2005 to January 2006, and agronomical evaluations were carried out two years and a half after the beginning of the experiment. Grain yield was evaluated during the first four harvests. Coffee plants derived from somatic embryogenesis show faster initial growth than those obtained from seeds, and had greater canopy diameter than plants with seminal origin 30 months after planting in field. The agronomic performace of $C$. arabica plants produced by somatic embryogenesis is similar to that of plants derived from seeds, and there are no agronomic restrictions for their use.
\end{abstract}

Index terms: Coffea arabica, vegetative growth, yield, propagation.

\section{Introdução}

O melhoramento genético do cafeeiro (Coffea arabica L.) por métodos convencionais é um processo demorado, e exige mais de 30 anos para obtenção de uma nova cultivar com características agronômicas geneticamente estáveis e pronta para o plantio comercial. Entretanto, o desenvolvimento de cultivares clonais requer menos tempo, cerca de 10 anos, o que permite a exploração da heterose de híbridos e a multiplicação de genótipos elite com características de interesse ainda em segregação, que dificilmente seriam reunidas em uma cultivar propagada sexuadamente.
A produtividade alcançada por cultivares clonais é, em geral, bem superior às obtidas por variedades híbridas sintéticas. Alguns autores verificaram entre 10 e $70 \%$ de heterose em cafeeiro (Etienne et al., 2002; Bertrand et al., 2005, 2006), com possibilidade de incorporação de genes complementares para resistência a pragas e doenças.

A pesquisa cafeeira tem buscado exaustivamente obter um protocolo que permita a propagação vegetativa in vitro de plantas $\mathrm{F}_{1}$ de $C$. arabica em escala comercial. A técnica de regeneração de plantas por embriogênese somática está bem estabelecida para o cafeeiro, e é possível produzir mudas clonais 
em larga escala com uso de biorreatores de imersão temporária (Afreen et al., 2002; Ducos et al., 2007, 2008). Etienne-Barry et al. (1999) demonstraram ser possível semear embriões germinados, produzidos em biorreatores de imersão temporária, diretamente no substrato utilizado para a produção de mudas. Neste processo, a conversão dos embriões em plântulas é realizada diretamente no substrato final, o que reduz custos, tempo, mão-de-obra e espaço laboratorial.

Há poucos relatos sobre o desempenho de plantas de $C$. arabica provenientes de embriogênese somática em condições de campo, sobretudo em relação ao seu crescimento vegetativo e às suas características produtivas.

O objetivo deste trabalho foi avaliar características agronômicas e morfológicas de plantas de C. arabica, cultivar Catuaí Vermelho IAC 44, produzidas por embriogênese somática.

\section{Material e Métodos}

O experimento foi instalado, em condições de campo, em janeiro de 2005, na Fazenda Experimental do Ministério da Agricultura, Pecuária e Abastecimento, Fundação Procafé, no Município de Varginha, no sul de Minas Gerais, a $21^{\circ} 34^{\prime} \mathrm{S}, 45^{\circ} \mathrm{C} 24^{\prime} 22^{\prime \prime W}$, e altitude média de $950 \mathrm{~m}$. O clima regional, segundo a classificação de Köppen, é mesotérmico úmido, com inverno seco e temperatura média de $16,0^{\circ} \mathrm{C}$, no mês mais frio (julho), e de $23,1^{\circ} \mathrm{C}$, no mês mais quente (fevereiro).

Os tratamentos consistiram de dois tipos de mudas de cafeeiro da cultivar Catuaí Vermelho IAC 44: plantas obtidas por embriogênese somática indireta e plantas obtidas por semente. As plantas propagadas por embriogênese somática indireta foram produzidas in vitro no laboratório da Embrapa Recursos Genéticos e Biotecnologia, Brasília, DF. Para aclimatização, as plantas foram transplantadas para sacos plásticos contendo substrato usualmente empregado para a formação de mudas de café. As plantas oriundas de sementes foram produzidas em viveiro convencional, em saquinhos, na modalidade de mudas de meio ano, sendo conduzidas de acordo com as práticas de manejo recomendadas para as mudas de cafeeiro (Reis \& Cunha, 2010).

Utilizou-se delineamento experimental em blocos ao acaso, com dez repetições e espaçamento de
$3,50 \times 0,80 \mathrm{~m}$. As parcelas foram constituídas por linhas de dez plantas, tendo-se considerado como úteis as oito plantas centrais. Foram utilizados os tratos culturais normalmente empregados para a cultura do café na região (Reis \& Cunha, 2010), e os tratos fitossanitários foram realizados acompanhando a sazonalidade da ocorrência de pragas e doenças.

As avaliações do desenvolvimento vegetativo das plantas tiveram início no sétimo mês após o plantio, quando elas apresentavam desenvolvimento aparentemente uniforme, embora fossem de origens diferentes. As plantas continuaram sendo avaliadas mensalmente, durante sete meses, entre junho de 2005 e janeiro de 2006, quanto à altura, ao número de ramos plagiotrópicos primários, ao número de nós do primeiro ramo plagiotrópico e ao comprimento do primeiro ramo plagiotrópico. A altura das plantas foi medida com régua graduada, do colo até o meristema apical. O número de ramos plagiotrópicos primários foi contado a partir do primeiro nó do ramo ortotrópico. $\mathrm{O}$ número de nós do primeiro ramo plagiotrópico e o comprimento do primeiro ramo plagiotrópico foram avaliados a partir da inserção no ramo ortotrópico até o meristema apical.

As avaliações agronômicas foram realizadas 30 meses após o plantio e compreenderam as seguintes características: produtividade, rendimento e tamanho de grãos, maturação, percentagem de frutos chochos, altura da planta e diâmetro de copa. O diâmetro de copa foi obtido ao medir-se, com régua graduada, a distância entre as duas extremidades dos ramos plagiotrópicos posicionados no terço médio da planta.

O estádio de maturação dos frutos foi avaliado pelo cálculo da percentagem de frutos verdes, cerejas, passas e secos, por contagem em amostras de 200 frutos por parcela. A percentagem de frutos chochos foi avaliada pela metodologia proposta por Antunes Filho \& Carvalho (1954), em que 100 frutos cereja são colocados em água e são considerados chochos os que permanecem na superfície.

As avaliações de produção foram realizadas em quatro colheitas, safras 2007/2008 e 2008/2009 e safras 2009/2010 e 2010/2011. A produção por planta em quilos de "café da roça", constituída pela mistura colhida de frutos verdes, maduros e secos, foi avaliada anualmente, com a colheita em julho. Na primeira colheita, separaram-se 2,0 L de "café da roça" de cada parcela para secagem ao sol. Depois de seco, o café 
em coco foi pesado, beneficiado e pesado novamente para calcular a produtividade e o rendimento, que foi obtido pela divisão do peso do café beneficiado pelo peso do café em coco. Utilizaram-se $200 \mathrm{~g}$ de café beneficiado de cada repetição para classificação em peneira quanto ao formato e à granulometria, tendose considerado apenas a subcategoria chato graúdo, ou seja, grãos retidos nas peneiras 19, 18 e 17 (Brasil, 2003).

Inspeções visuais foram realizadas para detectar variações somaclonais, com especial atenção para características vegetativas (diferenças na pigmentação de folhas, vigor e arquitetura das plantas), florescimento (ausência de flores, floração precoce ou tardia), frutificação (morfologia, tamanho e coloração, maturação tardia ou precoce, e anomalia dos grãos) e mortalidade das plantas provenientes de embriogênese somática.

Os dados foram analisados pelo Sisvar (Ferreira, 2008), e as médias foram comparadas pelo teste $\mathrm{F}$, a $1 \%$ de probabilidade. Para as avaliações de desenvolvimento vegetativo inicial, utilizou-se o esquema fatorial $2 \times 7$, tendo-se considerado a origem das plantas e o período de avaliação. A variável comprimento do primeiro ramo plagiotrópico foi transformada por meio da raiz quadrada, e as variáveis altura de planta (avaliada 30 meses após o plantio), produção e percentagem de grãos nos estádios verde, cereja, passa e seco sofreram transformação logarítmica, por apresentar heterogeneidade das variâncias.

\section{Resultados e Discussão}

Houve efeito significativo da origem das plantas e dos períodos de avaliação, com interação entre os fatores, para todas as características avaliadas (Tabela 1), o que indica que, ao longo do tempo, as plantas propagadas por embriogênese somática e por sementes apresentaram comportamentos diferentes.

Quanto à altura, observou-se que as plantas obtidas por embriogênese somática superaram as obtidas por semente, tendo-se observado uma diferença significativa durante todo o período de avaliação (Tabela 2). Houve maior emissão de ramos plagiotrópicos de cafeeiros propagados por embriogênese somática, o que corrobora outros relatos na literatura, de que plantas que apresentam maior altura tendem a apresentar maior número de ramos plagiotrópicos (Carvalho et al., 2008).

Houve diferença significativa do número de nós e comprimento do primeiro ramo plagiotrópico, que indicaram melhor desenvolvimento dessas características nas plantas propagadas por embriogênese somática, durante todo o período de avaliação (Tabela 2). Na ocasião do plantio, apesar de as mudas terem tamanhos semelhantes, observou-se que as plantas formadas in vitro apresentavam maior número de nós em comparação às oriundas de sementes. De acordo com Alves (2008), em cafeeiros, os ramos plagiotrópicos de primeira ordem se originam de gemas cabeça-de-série localizadas na axila das folhas presentes a partir do oitavo ou do décimo nó do ramo principal. Assim, é possível que as plantas provenientes de embriogênese somática tenham iniciado a formação de ramos plagiotrópicos mais precocemente, pois possuíam maior número de nós na época do plantio.

O sistema radicular provavelmente também é mais volumoso nas plantas propagadas por embriogênese somática, já que vários estudos têm mostrado relação positiva entre sistema radicular de plantas propagadas vegetativamente e o subsequente crescimento no pós-plantio, tanto em cafeeiros quanto em outras culturas (Struve et al., 1984; Paul et al., 1993; Partelli et al., 2006).

Tabela 1. Análises de variância, coeficiente de variação e médias gerais para altura (Alt), número de ramos plagiotrópicos (NRP), número de nós do primeiro ramo plagiotrópico (NNP) e comprimento do primeiro ramo plagiotrópico (CPP), para cafeeiros da cultivar Catuaí Vermelho IAC 44 provenientes de sementes e de embriogênese somática, obtidos do sétimo ao décimo terceiro mês após o plantio.

\begin{tabular}{lccccc}
\hline Fonte de variação & GL & Alt $(\mathrm{cm})$ & NRP & NNP & CPP $(\mathrm{cm})^{(1)}$ \\
\hline Bloco & 9 & 37,41 & 9,56 & 2,55 & 0,47 \\
Origem (O) & 1 & $1.716,67 * *$ & $868,12^{* *}$ & $256,20 * *$ & $22,64 * *$ \\
Erro (1) & 9 & 25,32 & 3,27 & 1,26 & 0,21 \\
Período (P) & 6 & $3.906,32^{* *}$ & $915,70 * *$ & $317,40 * *$ & $62,24 * *$ \\
O x P & 6 & $9,80^{* *}$ & $2,19 * *$ & $0,68 * *$ & $1,00 * *$ \\
Erro (2) & 108 & 2,37 & 1,03 & 0,24 & 0,02 \\
\hline Total & 139 & - & - & - & - \\
CV1 (\%) & - & 16,28 & 15,92 & 19,52 & 11,80 \\
CV2 (\%) & - & 4,88 & 8,93 & 8,53 & 2,78 \\
\hline Média & & 30,91 & 11,35 & 5,76 & 3,87 \\
\hline
\end{tabular}

${ }^{(1)}$ Os dados foram transformados pela raiz quadrada. $* *$ Significativo a $1 \%$ de probabilidade, pelo teste $\mathrm{F}$. 
A superioridade do desenvolvimento inicial de mudas propagadas por embriogênese somática também foi observada por outros autores. Menendez-Yuffa et al. (2010), ao comparar o desenvolvimento em viveiro de plantas de $C$. arabica cvs. Caturra e Costa Rica 95 (Catimor), provenientes de sementes e de embriogênese somática (somaclones), observaram que ao final de 21 semanas, os chamados somaclones apresentavam maior massa de matéria fresca.

Nas avaliações vegetativas, aos 30 meses, houve efeito significativo para diâmetro de copa das plantas. Como observado para o primeiro par de ramos plagiotrópicos, as plantas provenientes de embriogênese somática apresentaram maior diâmetro de copa que as plantas provenientes de sementes (Tabela 3). Para altura da planta, rendimento, percentagem de frutos chochos, estádio de maturação dos frutos e tamanho de grãos não houve diferenças significativas. As médias das características avaliadas estão de acordo com as obtidas em outros estudos com a cultivar Catuaí (Carvalho et al., 2006; Melo et al., 2006; Andrade et al., 2007).
Webster et al. (1990), ao trabalhar com abeto vermelho (Pinaceae), verificaram taxas de crescimento, altura e morfologia de brotos e raízes similares em plantas provenientes de sementes e de embriões somáticos. Plantas regeneradas de Trifolium fragiferum L., derivadas de embriões somáticos desenvolvidos em casa de vegetação, foram morfologicamente similares a plantas derivadas de sementes (Rybczynski, 1997). Díaz-Pérez et al. (1995), ao levar plantas micropropagadas de macieira para condições ex vitro, observaram que os sistemas radiculares desenvolvidos apresentaram características qualitativas similares às do sistema radicular de plantas provenientes de sementes.

Não foi observada qualquer alteração no fenótipo das plantas provenientes de embriogênese somática em relação à pigmentação de folhas, ao vigor e à arquitetura das plantas, à época de florescimento e de maturação de frutos e à mortalidade das plantas, o que corrobora os dados de Ducos \& Pétiard (2003) e Ducos et al. (2003), que não observaram variações somaclonais em plântulas somáticas de $C$. canephora conduzidas

Tabela 2. Valores médios de altura de plantas, números de ramos plagiotrópicos, número de nós do primeiro ramo plagiotrópico e comprimento do primeiro ramo plagiotrópico $(\mathrm{cm})$ para cafeeiros da cultivar Catuaí Vermelho IAC 44 provenientes de sementes e de embriogênese somática, obtidos do sétimo ao décimo terceiro mês após o plantio ${ }^{(1)}$.

\begin{tabular}{|c|c|c|c|c|c|c|c|}
\hline \multirow[t]{2}{*}{ Origem da planta } & \multicolumn{7}{|c|}{ Meses após o plantio } \\
\hline & 79 & 8 음 & 9음 & $10^{\circ}$ & $11^{\circ}$ & $12^{\underline{o}}$ & $13^{\circ}$ \\
\hline & \multicolumn{7}{|c|}{ Altura de plantas $(\mathrm{cm})$} \\
\hline Semente & $18,23 b$ & $21,35 b$ & $24,68 b$ & $29,94 b$ & $36,21 b$ & $43,45 b$ & $48,53 b$ \\
\hline \multirow[t]{2}{*}{ Embriogênese } & $21,49 a$ & $23,8 \mathrm{a}$ & $27,18 \mathrm{a}$ & $33,21 \mathrm{a}$ & $40,18 \mathrm{a}$ & $48,12 \mathrm{a}$ & $53,64 a$ \\
\hline & \multicolumn{7}{|c|}{ Números de ramos plagiotrópicos } \\
\hline Semente & $3,56 b$ & $4,88 b$ & $7,33 b$ & $10,99 b$ & $13,12 b$ & $15,87 \mathrm{~b}$ & $18,62 b$ \\
\hline \multirow[t]{2}{*}{ Embriogênese } & $7,92 \mathrm{a}$ & $9,07 \mathrm{a}$ & $11,82 \mathrm{a}$ & $15,49 \mathrm{a}$ & $17,90 \mathrm{a}$ & $20,85 a$ & $23,5 \mathrm{a}$ \\
\hline & \multicolumn{7}{|c|}{ Número de nós do primeiro ramo plagiotrópico } \\
\hline Semente & $1,49 b$ & $2,27 b$ & $3,53 b$ & $4,97 \mathrm{~b}$ & $61,8 b$ & $8,18 \mathrm{~b}$ & $10,02 b$ \\
\hline \multirow[t]{2}{*}{ Embriogênese } & $3,80 \mathrm{a}$ & $4,46 \mathrm{a}$ & $5,84 \mathrm{a}$ & $7,59 \mathrm{a}$ & $9,03 \mathrm{a}$ & $11,25 \mathrm{a}$ & $13,18 \mathrm{a}$ \\
\hline & \multicolumn{7}{|c|}{ Comprimento do primeiro ramo plagiotrópico $(\mathrm{cm})$} \\
\hline Semente & $3,70 \mathrm{~b}$ & $4,99 b$ & $8,18 b$ & $13,00 \mathrm{~b}$ & $18,80 \mathrm{~b}$ & $27,03 b$ & $33,30 b$ \\
\hline Embriogênese & $10,38 \mathrm{a}$ & $11,34 \mathrm{a}$ & $14,69 a$ & $19,51 \mathrm{a}$ & $24,80 \mathrm{a}$ & $32,17 \mathrm{a}$ & $38,17 \mathrm{a}$ \\
\hline
\end{tabular}

${ }^{(1)}$ Médias seguidas por letras iguais, nas colunas, não diferem entre si pelo teste de Scott Knot, a 5\% de probabilidade.

Tabela 3. Valores médios de altura da planta (Alt), diâmetro de copa (DC), rendimento (Rend), percentagem de grãos chochos (Ch), cereja (Cer), verde (Ve), passa (Pa), seco (Se) e chato graúdo (CG) da cultivar Catuaí Vermelho IAC 44 proveniente de sementes e de embriogênese somática, aos 30 meses após o plantio ${ }^{(1)}$.

\begin{tabular}{|c|c|c|c|c|c|c|c|c|c|}
\hline Origem & Alt & $\mathrm{DC}$ & Rend & $\mathrm{Ch}$ & Cer & $\mathrm{Ve}$ & $\mathrm{Pa}$ & $\mathrm{Se}$ & $\mathrm{CG}$ \\
\hline da planta & -------- & -------- & & & & $--(\%)$ & & & --------. \\
\hline Semente & $1,04 \mathrm{a}$ & $1,23 b$ & $52,41 \mathrm{a}$ & $4,00 \mathrm{a}$ & $41,28 \mathrm{a}$ & $55,2 \mathrm{a}$ & $1,6 a$ & $1,81 \mathrm{a}$ & $40,4 a$ \\
\hline Embriogênese & $1,08 \mathrm{a}$ & $1,38 \mathrm{a}$ & $49,72 \mathrm{a}$ & $6,70 \mathrm{a}$ & $34,99 a$ & $62,9 \mathrm{a}$ & $1,1 \mathrm{a}$ & $0,9 \mathrm{a}$ & $38,6 \mathrm{a}$ \\
\hline $\mathrm{CV}(\%)$ & 4,34 & 5,40 & 17,56 & 69,11 & 15,74 & 29,65 & 12,37 & 10,08 & 17,32 \\
\hline
\end{tabular}

${ }^{(1)}$ Médias seguidas por letras iguais, nas colunas, não diferem entre si pelo teste de Scott Knot, a 5\% de probabilidade. 
em campo, nas Filipinas e na Tailândia. Barry-Etienne et al. (2002) verificaram que a composição mineral de folhas de plantas provenientes de embriões somáticos regenerados em substratos é similar à de plantas provenientes de sementes.

A espécie arábica parece não apresentar estabilidade genética in vitro. Söndahl \& Lauritis (1992) estimaram a variabilidade em plantas micropropagadas em 10\%, enquanto Söndahl \& Baumann (2001) observaram que a frequência de variação somaclonal foi genótipo-dependente, com a incidência entre 3 e $30 \%$. Etienne \& Bertrand (2001) obtiveram resultados semelhantes, ao encontrar variação fenotípica de 3 a 10\% em 30.000 plantas de 20 clones de híbridos de C. arabica. A frequência de variantes somaclonais aumenta exponencialmente com a idade das suspensões embriogênicas usadas para regenerar as plantas, sendo de $1,3 \%$ para suspensões de três meses de idade, e de 6, 10 e 25\% para suspensões com idade de 6, 9 e 12 meses, respectivamente (Etienne \& Bertrand, 2001).

No presente trabalho, não foram observadas variações genéticas ou epigenéticas, provavelmente porque a busca por variantes, com base em critérios morfológicos, foi realizada em condições de campo. Entretanto, é possível que variantes somaclonais tenham ocorrido durante o cultivo in vitro, e que esses embriões ou plântulas tenham sido descartados durante o processo de produção de mudas, por não terem formado plântulas normais. Conforme Menendez-Yuffa et al. (2010), grande parte dos variantes morfológicos podem ser detectados ainda em viveiro, o que permite a eliminação de plantas com características não satisfatórias, e a significativa redução deste problema.

Ao se considerar os dois primeiros biênios (safras 2007/2008 e 2008/2009 e safras 2009/2010 e 2010/2011), observa-se que não houve diferença estatisticamente significativa entre a produtividade por hectare da cultivar Catuaí Vermelho IAC 44 proveniente de sementes e de embriogênese somática. A produtividade no primeiro e segundo biênios foi, respectivamente, de 27,63 e 34,31 sacas por hectare, em plantas provenientes de embriogênese somática, e de 23,20 e 27,81 sacas por hectare, em plantas provenientes de sementes. O coeficiente de variação para produtividade no primeiro e segundo biênios foi, respectivamente, de 18,33 e $19,18 \%$. Etienne \& Bertrand (2001) verificaram que a produtividade da primeira colheita de híbridos de C. arabica obtidos por estaquia e por embriogênese somática foi idêntica.

Esses resultados indicam que o desempenho agronômico de plantas de $C$. arabica produzidas por embriogênese somática é semelhante ao de plantas oriundas de sementes. Portanto, a embriogênese somática pode ser utilizada como método de propagação de mudas de C. arabica, com um grande potencial a ser explorado.

\section{Conclusões}

1. Cafeeiros provenientes de embriogênese somática apresentam desenvolvimento inicial mais rápido que plantas do mesmo genótipo obtidas de sementes.

2. Aos 30 meses após plantio no campo, plantas de Coffea arabica provenientes de embriogênese somática apresentam diâmetro de copa superior ao de plantas de origem seminal.

3. O desempenho agronômico de plantas de Coffea arabica produzidas por embriogênese somática é semelhante ao de plantas oriundas de sementes.

\section{Referências}

AFREEN, F.; ZOBAYED, S.M.A.; KOZAI, T. Photoautotrophic culture of Coffea arabusta somatic embryos: development of a bioreactor for large-scale plantlet conversion from cotyledonary embryos. Annals of Botany, v.90, p.21-29, 2002.

ALVES, J.D. Morfologia do cafeeiro. In: CARVALHO, C.H.S. (Ed.). Cultivares de café: origem, características e recomendações. Brasília: Embrapa Café, 2008. p.35-56.

ANDRADE, A.C. de; MELO, B. de; PAULA, R.C. de. Avaliação de linhagens das cultivares de cafeeiro Catuaí Vermelho e Amarelo, em solos sob vegetação de cerrado, do município de Uberlândia-MG. Horizonte Científico, v.1, p.1-16, 2007.

ANTUNES FILHO, H.; CARVALHO, A. Melhoramento do cafeeiro: VII - ocorrência de lojas vazias em frutos de café "Mundo Novo". Bragantia, v.13, p.165-179, 1954.

BARRY-ETIENNE, D.; BERTRAND, B.; VASQUEZ, N.; ETIENNE, H. Comparison of somatic embryogenesis-derived coffee (Coffea arabica L.) plantlets regenerated in vitro or ex vitro: morphological, mineral and water characteristics. Annals of Botany, v.90, p.77-85, 2002.

BERTRAND, B.; ETIENNE, H.; CILAS, C.; CHARRIER, A.; BARADAT, P. Coffea arabica hybrid performance for yield, fertility and bean weight. Euphytica, v.141, p.255-262, 2005.

BERTRAND, B.; VAAST, P.; ALPIZAR, E.; ETIENNE, H.; DAVRIEUX, F.; CHARMETANT, P. Comparison of bean biochemical composition and beverage quality of Arabica hybrids involving Sudanese-Ethiopian origins with traditional varieties 
at various elevations in Central America. Tree Physiology, v.26, p.1239-1248, 2006.

BRASIL. Ministério da Agricultura, Pecuária e Abastecimento. Instrução normativa $\mathrm{n}^{\mathrm{o}} 8$, de 11 de junho de 2003. Aprova o regulamento técnico de identidade e de qualidade para a classificação do café beneficiado grão cru. Diário Oficial [da] República Federativa do Brasil, 14 jun. 2003. Seção 1, p.4.

CARVAlHO, G.R.; BARTHOLO, G.F.; MENDES, A.N.G.; NOGUEIRA, Â.M.; MAGALHÃES, M.M. Seleção de progênies oriundas do cruzamento entre 'Catuaí' e 'Mundo Novo' em diferentes regiões do Estado de Minas Gerais. Bragantia, v.65, p.583-590, 2006.

CARVALHO, M.; JESUS, A.M.S.; CARVALHO, S.P. de; GOMES, C.N.; SOARES, A.M. Comportamento em condições de campo de cafeeiros (Coffea arabica L.) propagados vegetativamente e por semeadura. Coffee Science, v.3, p.108-114, 2008.

DÍAZ-PÉREZ, J.C.; SUTTER, E.G.; SHACKEL, K.A. Acclimatization and subsequent gas exchange, water relations, survival and growth of microcultured apple plantlets after transplanting them in soil. Physiologia Plantarum, v.95, p.225-232, 1995.

DUCOS, J.P.; ALENTON, R.; REANO, J.F.; KANCHANOMAI, C.; DESHAYES, A.; PETIARD, V. Agronomic performance of Coffea canephora $\mathrm{P}$. trees derived from large-scale somatic embryo production in liquid medium. Euphytica, v.131, p.215-223, 2003.

DUCOS, J.P.; LABBE, G.; LAMBOT, C.; PETIARD, V. Pilot scale process for the production of pre-germinated somatic embryos of selected robusta (Coffea canephora) clones. In vitro Cellular and Developmental Biology-Plant, v.43, p.652-659, 2007.

DUCOS, J.P.; PÉTIARD, V. Propagation de clones de Robusta (Coffea canephora P.) par embryogenése somatique en milieu liquide. In: EL HADRAMI, I.; DAAYF, F. (Ed.). Biotechnologies vegetales: de la structure des genomes a l'Amelioration des plantes. Marrakech: El Watanya, 2003. p.142-159.

DUCOS, J.P.; TERRIER, B.; COURTOIS, D.; PÉTIARD, V. Improvement of plastic-based disposable bioreactors for plant science needs. Phytochemistry Reviews, v.7, p.607-613, 2008.

ETIENNE, H.; ANTHONY, F.; DUSSERT, S.; FERNANDEZ, D.; LASHERMES, P.; BERTRAND, B. Biotechnological application for the improvement of coffee (Coffea arabica L.). In vitro Cellular and Development Biology - Plant, v.38, p.129-138, 2002.

ETIENNE, H.; BERTRAND, B. Trueness-to-type and agronomic characteristics of Coffea arabica trees micropropagated by the embryogenic cell suspension technique. Tree Physiology, v.21, p.1031-1038, 2001.
ETIENNE-BARRY, D.; BERTRAND, B.; VASQUEZ, N.; ETIENNE, H. Direct sowing of Coffea arabica somatic embryos mass-produced in a bioreactor and regeneration of plants. Plant Cell Reports, v.19, p.111-117, 1999.

FERREIRA, D.F. SISVAR: um programa para análises e ensino de estatística. Revista Symposium, v.6, p.36-41, 2008.

MELO, B. de; MARCUZZO, K.V.; TEODORO, R.E.F. Avaliação de linhagens de cafeeiro, cultivar Catuaí, em Uberlândia-MG. Ceres, v.53, p.614-618, 2006.

MENENDEZ-YUFFA, A.; BARRY-ETIENNE, D.; BERTRAND, B.; GEORGET, F.; ETIENNE, H. A comparative analysis of the development and quality of nursery plants derived from somatic embryogenesis and from seedlings for large-scale propagation of coffee (Coffea arabica L.). Plant Cell, Tissue and Organ Culture, V.102, p.297-307, 2010.

PARTELLI, F.L.; VIEIRA, H.D.; SANTIAGO, A.R.; BARROSO, D.G. Produção e desenvolvimento radicular de plantas de café 'Conilon' propagadas por sementes e por estacas. Pesquisa Agropecuária Brasileira, v.41, p.949-954, 2006.

PAUL, A.D.; FOSTER, G.S.; LESTER, D.T. Field performance, C effects, and their relationship to initial rooting ability for western hemlock clones. Canadian Journal of Forest Research, v.23, p.1947-1952, 1993.

REIS, P.R.; CUNHA, R.L. da. Café arábica: do plantio à colheita. Lavras: EPAMIG, 2010. 896p.

RYBCZYNSKI, J. Plant regeneration from highly embryogenic callus, cell suspension and protoplast cultures of Trifolium fragiferum. Plant Cell, Tissue and Organ Culture, v.51, p.159-170, 1997.

SÖNDAHL, M.R.; BAUMANN, T.W.Agronomy II: developmental and cell biology. In: CLARKE, R.J.; WITZTHUN O.J. (Ed.). Coffee: recent developments. Oxford: Blackwell Science, 2001. p.202-220.

SÖNDAHL,M.R.;LAURITIS,J.A.Coffee.In:HAMMERSCHLAG, F.; LITZ, R.E. (Ed.). Biotechnology of perennial fruit crops. London: CAB International, 1992. p.401-420.

STRUVE, D.K.; MCKEAND, S.E. Growth and development of eastern white-pine rooted cuttings compared with seedlings through 8 years of age. Canadian Journal of Forest Research, v.20, p.365-368, 1984.

WEBSTER, F.B.; ROBERTS, D.R.; MCINNIS, S.M.; SUTTON, B.C.S. Propagation of interior spruce by somatic embryogenesis. Canadian Journal of Forest Research, v.20, p.1759-1765, 1990.

Recebido em 30 de setembro de 2010 e aprovado em 3 de março de 2011 